\title{
CONF-9505105--6
}

\section{Fast Wave Current Drive Modeling Using the Combined RANT3D and PICES Codes*}

\author{
E. F. Jaeger ${ }^{\dagger}$, M. Murakami, $\nmid$ D. C. Stallings ${ }^{\dagger}$, M. D. Carter ${ }^{\dagger}$, C. Y. Wang ${ }^{\dagger}$, \\ J. D. Galambos ${ }^{\dagger}$, D. B. Batchelor ${ }^{\dagger}$, F. W. Baity ${ }^{\dagger}$, G. L. Bell, $\dagger$ \\ J. B. Wilgen $\dagger$, S. C. Chiu $\ddagger$, J. S. DeGrassie $\ddagger$, C. B. Forest ${ }^{\ddagger}$, K. Kupfer ${ }^{\dagger}$,

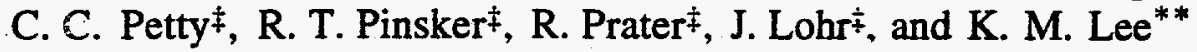 \\ †Oak Ridge National Laboratory, Oak Ridge, Tennessee 37831-807I \\ $¥$ General Atomics, San Diego, California $92186-9784$ \\ ${ }^{* *}$ University of California, Los Angeles, California 90024-1597 \\ † ORISE Postdoctoral Fellow at General Atomics, San Diego, California 92186-9784
}

\begin{abstract}
Two numerical codes are combined to give a theoretical estimate of the current drive and direct electron heating by fast waves launched from phased antenna arrays on the DIII-D tokamak. Resuits are compared with experiment.
\end{abstract}

Fast wave current drive (FWCD) efficiency in tokamaiss is critically dependent on the shape of the power spectrum launched by phased antenna arrays. Recently, it has been found that three-dimensional (3-D) rather than two-dimensional (2-D) antenna models are needed to accurately describe this spectrum. Therefore, to obtain the most accurate theoretical estimate possible of current drive (CD), two numerical codes have been combined: the RANT3D antenna design code [1] and the PICES full-wave propagation and absorption code [2]. Both codes have been benchmarked individually $[1,3]$ against data from the Tokamak Fusion Test Reactor (TFTR). In addition, PICES has been benchmarked [4] against a number of other full-wave and ray tracing codes for ion cyclotron range of frequency (ICRF) heating scenarios on the International Thermonuclear Experimental Reactor (ITER). The purpose of the present work is to benchmark the combined RANT3D - PICES code against detailed FWCD and direct electron heating (DEH) data from the DIII-D tokamak.

PICES is a global wave propagation code that uses poloidal and toroidal mode expansions to solve the reduced order [2] wave equation for the ICRF electric field $\vec{E}$ in toroidal geometry,

\footnotetext{
* Research sponsored by the Office of Fusion Energy, L.S. Department of Energy, under contract No. DE-AC05-84OR21400 with Martin Marietta Energy Systems, Inc. and U.S. DOE Contracts DE-AC03-89ER51114, Grant DE-FG03-86ER53225, and in part by an appointment to the U.S. Department of Energy, Fusion Energy Postdoctoral Research Program at General Atomics administered by the Oak Ridge Institute for Science and Education.
} 


\section{DISCLAIMER}

Portions of this document may be illegible in electronic image products. Images are produced from the best available original document. 


$$
-\nabla \times \nabla \times \vec{E}+\frac{\omega^{2}}{c^{2}}\left(\vec{E}+\frac{i}{\omega \varepsilon_{0}} \vec{J}_{p}\right)=-i \omega \mu_{0} \vec{J}_{e x}
$$

In Eq. (1), the plasma current $\vec{J}_{p}$ is represented as a Fourier sum over poloidal and toroidal harmonics. The external current, $\vec{J}_{\text {ext }}$, can be used to represent an ICRF antenna as in Ref. 2. However, in this paper, we set $\vec{J}_{e x}=0$ and drive the radio frequency $(R F)$ electric field instead by imposing boundary conditions directly on the tangential component of $\vec{E}$ at the outer flux surface boundary in the PICES code. These boundary conditions are provided by the 3-D antenna design code RANT3D [1]. This code solves for the wave electric field $\vec{E}$ with outgoing wave boundary conditions for a slab plasma in front of a complicated 3-D antenna structure as shown in Fig. 1. The plasma density profile in front of the antenna is reconstructed from fits to Thompson scattering data in the bulk plasma and from reflectometer data in the scrape-off plasma.

Parameters used to characterize DIII-D shot 84280 for these calculations are $\mathrm{R}_{0}=1.70 \mathrm{~m}, \mathrm{~B}_{0}=2.08 \mathrm{~T}, \mathrm{I}_{\mathrm{p}}=1.40 \mathrm{MA}, \mathrm{a}=0.63 \mathrm{~m}, \kappa=1.89$ (elongation) $\delta \approx 0.72$ (triangularity), and $\mathrm{Z}_{\text {eff }} \approx 2.5$. The dashed curves in Fig. 2 show the radiated power spectrum calculated by RANT3D with $-\pi / 2$ phasing for 60 and $90 \mathrm{MHz}$ antenna geometries. The spectrum is slightly less directional at $90 \mathrm{MHz}$ than at $60 \mathrm{MHz}$. Fourier components of the tangential electric field evaluated at the dashed line in Fig. 1 are used as boundary conditions at the outermost flux surface of the PICES calculation. Figure 3 shows a typical PICES result for DII-D shot 84280 in a deuterium plasma with ICRF heating at $f=60 \mathrm{MHz}, B=2 \mathrm{~T}$, and estimated $1 \%$ residual hydrogen. The fast wave propagates inward from the low field (right) side and is absorbed near the magnetic axis by electron Landau damping and magnetic pumping. In addition, there is cyclotron damping of the fast wave at the second harmonic resonance of the minority hydrogen, which is near the magnetic axis at $60 \mathrm{MHz}$. There can be mode conversion to ion Bernstein waves (IBW) at this resonance, but IBW is suppressed in PICES by the reduced order algorithm [2], which improves numerical stability. The third harmonic resonance of the majority deuterium is located on the high field (left) side of the plasma and contributes little to wave damping and absorption. A right-hand cutoff $\left(n_{l l}^{2}=R\right)$ prevents propagation of the fast wave on the extreme high field (left) side. The spectrum of absorbed power from the RANT3D-PICES modeling is shown in the solid curves in Fig. 2. Fluctuations in the absorbed power are due to constructive and destructive interference as the waves are reflected from the right-hand cutoff.

Power deposition and integrated power profiles are shown in Fig. 4(a) assuming a $1 \%$ fraction of hydrogen in the plasma. At $60 \mathrm{MHz}$, ion cyclotron damping at the second harmonic resonance of hydrogen accounts for $32 \%$ of the absorbed power. The remaining $68 \%$ is absorbed by electrons. At $90 \mathrm{MHz}$, the 
second harmonic hydrogen resonance is located farther to the high field side, and only about $5 \%$ of the power is lost to ions. The remaining $95 \%$ is absorbed by electrons. The larger fraction of electron heating in this case leads to a higher $C D$ efficiency at $90 \mathrm{MHz}$.

Experimental analysis of the electron power deposition profiles is carried out using electron cyclotron emission radiometer signals in response to RF power modulation. Both 60 and $90 \mathrm{MHz}$ RF power was $50 \%$ modulated with square waves at $50 \mathrm{~Hz}$. Figure 5 shows the local electron power deposition profiles (for a 1-MW power coupled to the plasma) and volume-integrated power as a function of the normalized minor radius. The absorbed power profile is centrally peaked but is broader than that calculated with the model. The volume-integrated power is about $90 \%$ of the predicted DEH.

Driven current profiles for both frequencies are calculated from numerical fits to the Fokker-Planck calculations of Karney and Ehst [5], and plotted in Fig. 4(b) vs flux surface label $\rho$. CD efficiency is defined by $\gamma=\left(\bar{n}_{e} R / 10^{20}\right) I / P_{r f}$, where $I$ is the current driven for a total coupled power $P_{r f}$. For each case in Fig. $4 P_{r f}$ has been normalized to the experimental value of power coupled by the antenna. Approximately $100 \mathrm{kA}$ are driven for $0.92 \mathrm{MW}$ coupled by the $60 \mathrm{MHz}$ antenna, giving an efficiency $\gamma \approx 0.030 \mathrm{AW} / \mathrm{m}^{2}$. About $80 \mathrm{kA}$ are driven for $0.66 \mathrm{MW}$ coupled by the $90 \mathrm{MHz}$ antenna for an efficiency $\gamma=0.033 \mathrm{~A} / \mathrm{W} / \mathrm{m}^{2}$. The somewhat higher efficiency at $90 \mathrm{MHz}$ is the result of absence of the parasitic power loss to the hydrogen ions. Raising the fraction of hydrogen to $2 \%$ gives a parasitic loss to the hydrogen of about $40 \%$ at $60 \mathrm{MHz}$ and a correspondingly lower efficiency of $0.024 \mathrm{~A} / \mathrm{W} / \mathrm{m}^{2}$ with $80 \mathrm{kA}$ driven current. Combined current for both 60 and $90 \mathrm{MHz}$ antennas is in approximate agreement with the experiment [6]. Efficiency varies from 0.024 to $0.033 \mathrm{~A} / \mathrm{W} / \mathrm{m}^{2}$. Work in progress will allow the equilibrium magnetic field to be read directly from EQDSK files for a particular shot. Also, boundary values for the tangential electric field will be transferred from RANT3D to PICES in real space rather than in Fourier space.

\section{REFERENCES}

1. Carter, M. D. et al., "Three-Dimensional Modeling of ICRF Launchers for Fusion Devices," to be published in Nuch Fusion.

2. Jaeger, E. F., Batchelor, D. B., and Stallings, D. C.. Nucl. Fusion 33 (1993) 179.

3. Murakami, M., et al., Fusion Technol. 27 (1995) 131.

4. Becoulet, A.. private communication. April 1995.

5. Ehst. D. A., and Karney, C. F. F., Nuct. Fusion 31 (1991) 1933.

6. Forest. C. B., et al., "Experimentally Determined Profiles of Fast Wave Current on DIII-D." this conference.

\section{DISCLAIMER}

This report was prepared as an account of work sponsored by an agency of the United States Government. Neither the United States Government nor any agency thereof, nor any of their employees, makes any warranty, express or implied, or assumes any legal liability or responsibility for the accuracy, completeness, or usefulness of any information, apparatus, product, or

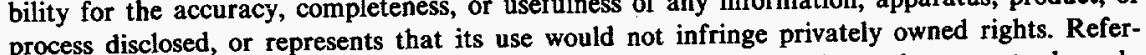
ence herein to any specific commercial product, process, or service by trade name, trademark, manufacturer, or otherwise does not necessarily constitute or imply its endorsement, recommendation, or favoring by the United States Government or any agency thereof. The views and opinions of authors expressed herein do not necessarily state or reflect those of the United States Government or any agency thereof. 


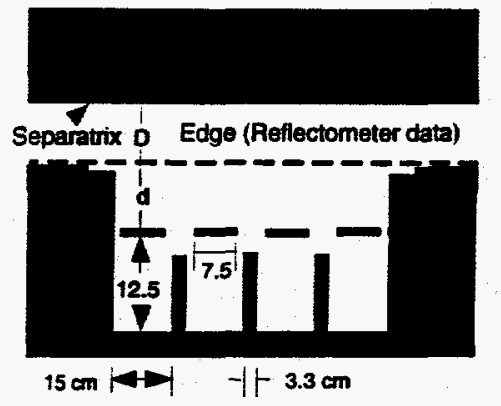

Fig. 1. RANT3D geometry for the DIII-D $90 \mathrm{MHz}$ antenna.

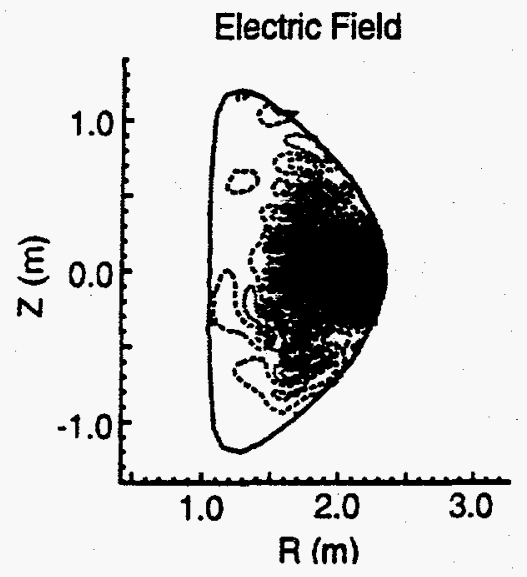

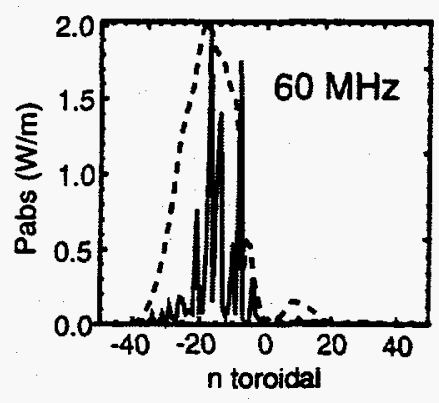

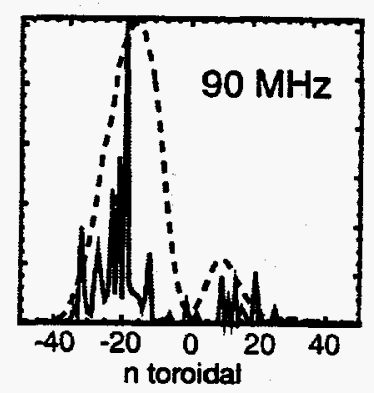

Fig. 2. Power spectrum for DIII-D with $-\pi / 2$ phasing.

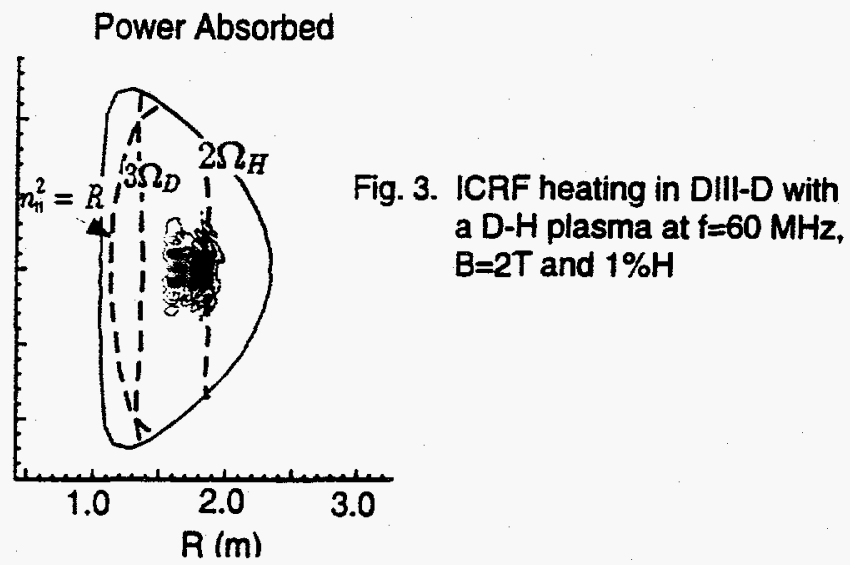

$60 \mathrm{MHz}$ (SPA=.132)

$90 \mathrm{MHz}(\mathrm{SPA}=.107)$
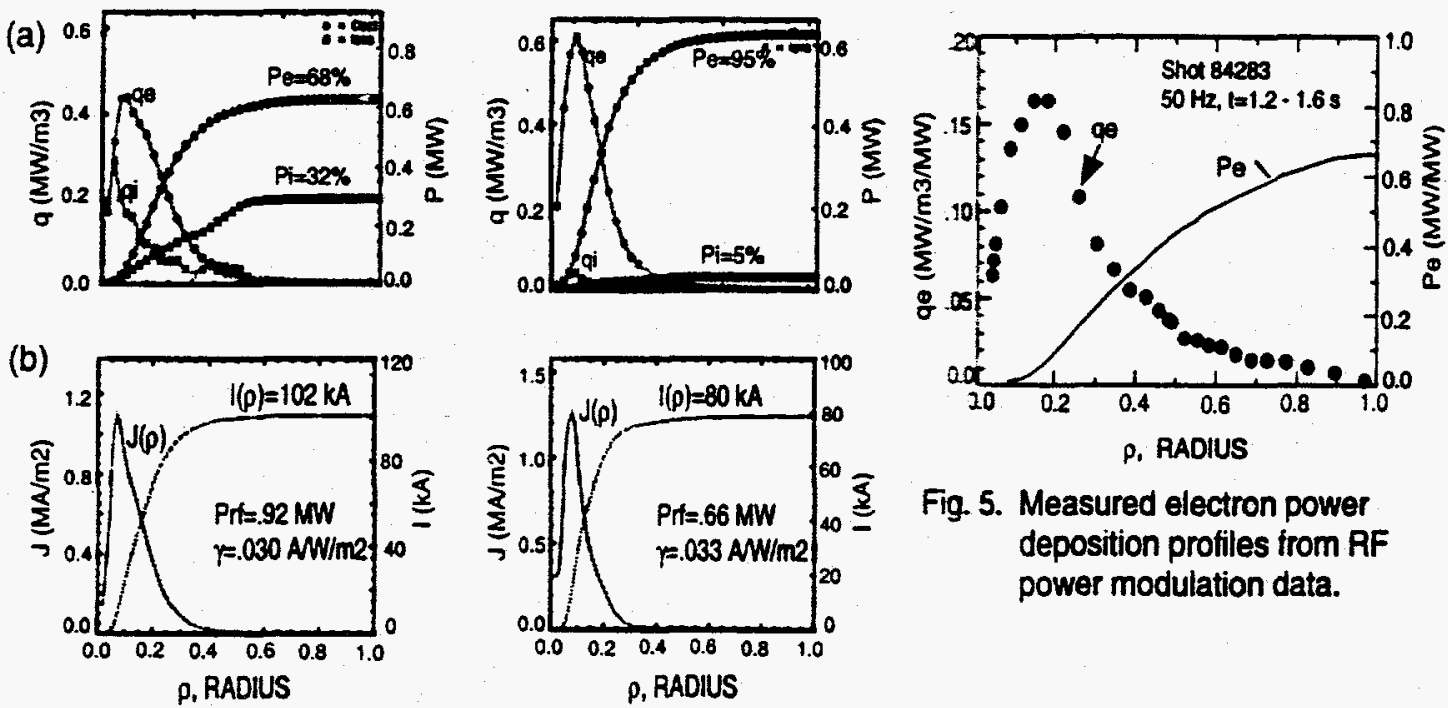

Fig. 5. Measured electron power deposition protiles from RF power modulation data.

Fig. 4. Power deposition (a), and driven current profiles (b) from RANT3D-PICES modeling of DIII-D shot 84280 assuming $1 \% \mathrm{H}$ 